\title{
CAREER ATTITUDES OF STUDENTS IN THE PROCESS OF TRANSITION TO UPPER SECONDARY EDUCATION \\ Desislava Aleksandrova ${ }^{1}$, Dimitar Iskrev $^{2}$
}

\begin{abstract}
The behavioural dimensions of students' career choices in the process of transition to upper secondary education are of particular pedagogical interest. Studying career attitudes will not only contribute to outlining the status, completeness and effective use of personal pathsbut will also provide efficient means by which the future professional career will be pursued.

The conducted original study included 64 seventh-grade students from educational institutions, typical for the Bulgarian education system. The behavioural dimensions of a career choice, i.e. Planning and exploration, were studied using a selfevaluation rating scale. It included a series of questions for the respondent, to self-report on the degree of expression of the relevant aspect of their career choice.

The actual expression of career attitudes in seventh-graders is determined by a small number of internal factors (in most cases two) of well-defined nature for each career development component. For the planning part, they are related to specifying the perceptions of career goals and their temporal boundaries. For the exploration part, the factors reflect the nature of the information source, i.e. informal or institutionalized.

The study of the behavioural dimensions of career development forms a basis for conclusions on students' readiness to make informed career choices and their needs in this regard. In this way, the place and role of the school as a socializing institution in the process of personal development are outlined.
\end{abstract}

UDC Classification: 37.04, DOI: https://doi.org/10.12955/pss.v1.37

Keywords: career development, career attitudes, educational transition, career planning and career exploration

\section{Introduction}

A person's career development is a process of clearly defined behavioural dimensions. They reflect an individual's attitude to a professional career and disposition to have a certain type of behaviour in relation thereto. In particular, career development contains (Lokan, 1984; Savickas, 1994): professional awareness, willingness to make appropriate plans, desire to explore the world of work, knowledge of career-related changes resulting from increasing age and social responsibility, knowledge of the world of work and the appropriate professions for the individual.

The methodology used included a set of statements related to the future profession. Each statement is evaluated by the subject on a four- or five-step verbal scale.

\section{Career planning and career exploration in seventh-graders}

To reveal the relationship between career planning activities, the starting point of the analysis was seventh-graders, who have demonstrated an attitude to take different steps to clarify their professional future. They state that they have made clear plans in the direction of their chosen career path and have begun to implement them in practice. Those of them who have not yet taken concrete actions state that they know what to do, to implement their career plans, i.e. they are aware of the ways and means of how to implement them. Seventh-graders who have given such answers, show a clear attitude to be active moderators of their career development. The proportion of planned activities of that group of seventhgraders, compared to the total number of surveyed students is shown in the diagram below (Figure 1).

Predominant activities are those activities that are directly related to learning or having a similar behavioural pattern. Two-thirds of the surveyed seventh-graders (68\%), tend to rely on their academic achievements as a mean of achieving specific career goals when designing their careers. In reality, this means a high-grade average of the diploma subjects and/or the subjects required to apply for a higher education degree. Similar in the content are having good academic achievements in subjects that will find immediate application in the future training and/or profession (67\%) or participating in extracurricular and after-school activities such as circles, electives, clubs, etc. (72\%). The knowledge and skills acquired here, in addition, to clarify career plans, often earn the status of an essential component of a specific career goal. In carrying out such activities, there is not always a real dimension

\footnotetext{
1 South-West University of Blagoevgrad, Faculty of Engineering, Technology Training and Vocational Education Department, desislava_alexandrova@abv.bg

2 South-West University of Blagoevgrad, Faculty of Engineering, Technology Training and Vocational Education Department, d_iskrev@abv.bg
} 
of feedback on correspondence between the developed image of the profession and the available competences. Their speculative juxtaposition dominates.

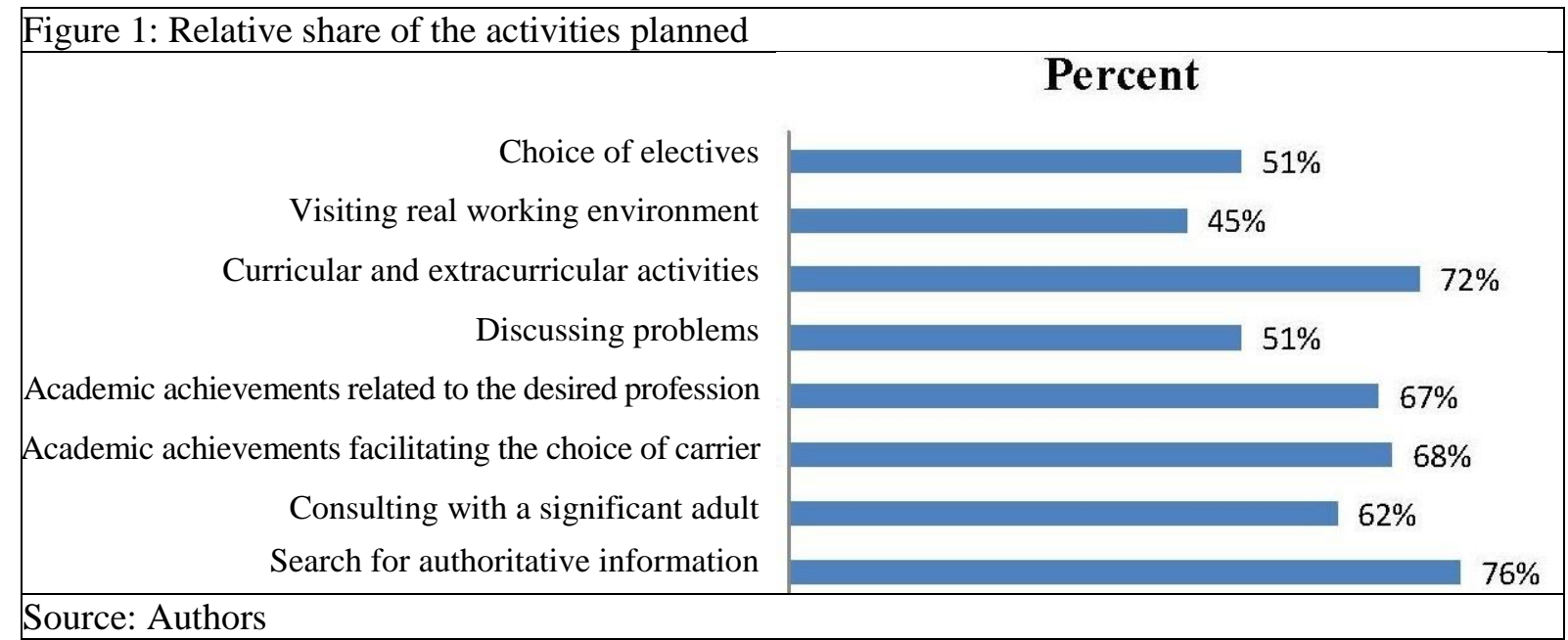

A similar behavioural model is a search for authoritative information from institutions and people, the contact which will help a seventh-grader to clarify his or her career plans. The actions taken in this direction are conversations with significant adults (62\%) to identifying problems that may make it difficult for a young person to obtain the desired training or profession (51\%). Majority of seventhgraders in the surveyed group expressed a clear attitude to have this type of behavior. A much smaller proportion of students intended to behave in a way, to test their strengths to clarify their immediate or distant future, through methods such as visiting a real working environment (45\%).

The modern seventh-grader, in the process of planning his or her professional career, prefers activities in which information accumulation dominates while dealing with passive models of the profession. Direct contact with a real working environment, as a type of behaviour to clarify a student's professional future, is comparatively less sought after. However, such contact helps to adequately verify a young person's suitability for a particular professional activity. Based on practical indicators, adjustments are made to the behavioral determinants of career development (interests, desires and inclinations) and the knowledge about oneself is deepened. In this regard, we would like to note that testing one's strengths and abilities in a variety of situations, is considered a major career research method for adolescents.

Seventh-graders' attitudes on information clarity about various aspects of their desired profession (job) reflect a student's subjective assessment of the extent to which the created image of that job, corresponds to reality. Figure 2 below shows the responses (in relative shares) for the different professional characteristics. The diagram indicates the assessment of those seventh-graders who have defined their knowledge within the top two levels of the verbal scale given to them. They believe that they know "much" or "very much" about the relevant aspect of the profession. The diagram shows the level of expression, of the formed attitude towards information clarity for the preferred profession, in this group of students.

Most of the seventh-graders with a high level of information clarity, self-assess that they have complete knowledge of professional characteristics, such as abilities (71\%), specific duties of the people who practice the profession $(67 \%)$, ways to get into it $(67 \%)$, working conditions $(62 \%)$, education and training $(60 \%)$. Comparatively, some more unfamiliar aspects of the profession remain unknown such as growth potential $(57 \%)$, working time $(54 \%)$, and starting salary $(53 \%)$. The first group of characteristics are relatively stable temporally. They are determined by the generic attributes of the content of a profession, that is, they refer to a group of professions, a professional field, or a field of work. They are elements of the so-called basal professional describing the general basic characteristics of the type of professional activity performed in various ways in more or less distinctive workplaces. The other aspects depend largely on a fixed professional position or role and they rather belong to a specific professional describing the professional activity performed in a particular workplace or a particular variant of the basic profession. 


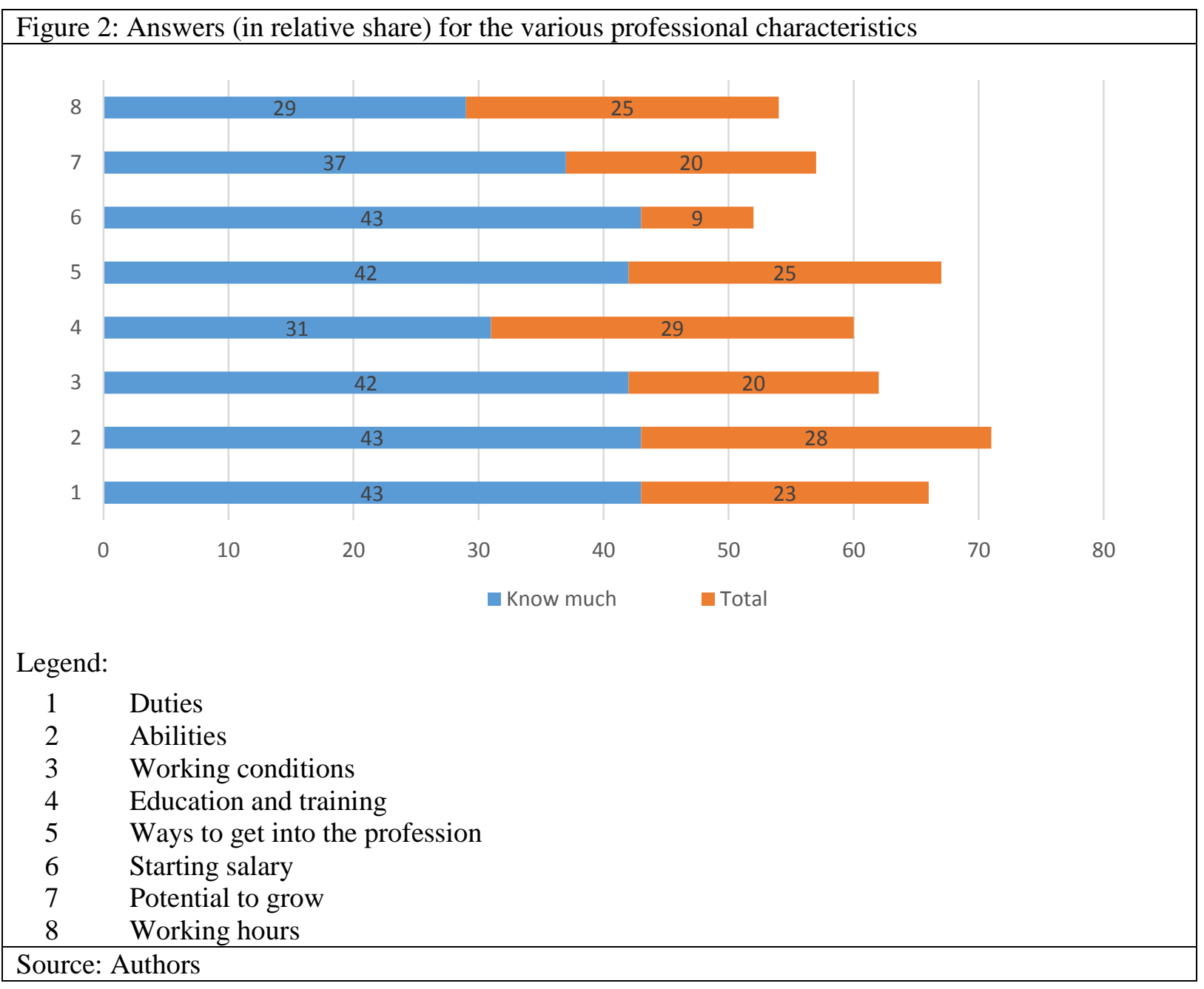

The obtained results can be allocated to the structural components of personal career plans of seventhgraders. The disclosed contents of the attitudes of modern seventh graders, towards information clarity, shows that they have a more accurate idea of the internal and external conditions for the achievement of the main career goal pursued. More vaguely outlined are the specific career development goals as well as the ways and means of achieving them. Planning a career for seventh-graders is generally done by knowing the overall desired result, without detailing its specific outlines. This is supported by seventhgraders' assessment of their life-after-high-school plans. The predominate (56\%) assessments are those according to which, in the personal plans of seventh-graders some components that are not defined and definitive enough for the student.

Career exploration reflects the attitude towards different sources of professional information. The importance of an information source for a young person is determined by their attitude to turn for help from it, in the development of their career plans. Furthermore, the personal use of an information source for a seventh-grader can be deduced from the actual use of the source and the assessment of the qualities of the information received. The ranking of information sources according to the relative frequency of students who demonstrate an attitude of personal importance and usefulness of that source is shown in Table 1 .

Seventh-graders identify the representatives of educational institutions, such as teachers, other pedagogues, psychologists and professionals in vocational guidance to be of relatively less personal importance and usefulness in career exploration The attitude to seek authoritative career information generally from outside the school, is an indicator that at present, the social institution has a weaker position in shaping students' real career plans. Given the dominant role of sources that are outside the educational field, there are objective prerequisites for students, to form an inadequate idea of their preferred profession and career. In most cases, contact with such sources is situational and not systematic. This determines the need for pedagogical mediation in the use for this category of sources. 
This can guarantee the formation of balanced career attitudes among students. Consistency of career attitudes is a key to the young person's ability to manage his or her professional future.

\begin{tabular}{|l|c|c|c|c|}
\hline Table 1: Relative share and rank of information sources in high school students (N = 64) \\
\hline Information source & Importance & Rank & Usefulness & Rank \\
\hline Parents, relatives & 78 & $\mathbf{1}$ & 73 & $\mathbf{1}$ \\
\hline Peers, friends & 48 & $\mathbf{5}$ & 32 & $\mathbf{5 / 6}$ \\
\hline Education professionals & 40 & $\mathbf{6 / 7 / 8}$ & 28 & $\mathbf{8}$ \\
\hline Teachers & 40 & $\mathbf{6 / 7 / 8}$ & 31 & $\mathbf{7}$ \\
\hline Adults outside school & 40 & $\mathbf{6 / 7 / 8}$ & 32 & $\mathbf{5 / 6}$ \\
\hline Written sources & 54 & $\mathbf{4}$ & 37 & $\mathbf{4}$ \\
\hline Electronic and social media & 68 & $\mathbf{3}$ & 51 & $\mathbf{2}$ \\
\hline People in the preferred profession & 70 & $\mathbf{2}$ & 50 & $\mathbf{3}$ \\
\hline Source: Authors & 75 \\
\hline
\end{tabular}

\section{Factors affecting the choice of career of seventh-graders}

It is of scientific interest to look for common internal determinants of the actual expression, of the dimensions of career development in the process of transition from school to active working life. This will help in better understanding of the hidden personal reasons for their origination, applicable for seventh-graders. In turn, the idea of career development becomes more comprehensive and profound. (Jordaan \& Heyde, 1979; Tang, Pan \& Newmeyer, 2008).

The data obtained was subject to factor analysis. The principal factor method and subsequent varimax rotation were used. The basic scales of the methodology were analyzed. The results for each are shown in a table.

When planning a professional career, seventh-graders are guided by three main factors. The first involves clarifying the idea of the preferred profession (Table 2). This includes, primarily, the subjectively of the recognized amount of knowledge about the various professional aspects. The structure of this factor also includes activities to clarify a professional future by visiting a real working environment. The young man associates these activities, above all, with clarifying the outline of personally liked and desired profession. We believe this is due to their more direct attachment to the real world of work. The common thing between the questions building this factor is that they reflect careerplanning aspects aimed at providing a real-world view of a particular profession. This factor can be defined as "Clarification of the Preferred Profession".

\begin{tabular}{|c|c|c|c|}
\hline Questions & Factor 1 & Factor 2 & Factor 3 \\
\hline Q1: Search for authoritative information & & .71 & \\
\hline Q2: Consulting with a significant adult & & .54 & \\
\hline Q3: High grades in subjects helping the career choice & & .69 & \\
\hline Q4: High grades in subjects related to the desired profession & & .57 & \\
\hline Q5: Discussing problems & & .45 & \\
\hline Q6: Curricular and extracurricular activities & & .42 & \\
\hline Q7: Visiting a real working environment & .32 & & \\
\hline Q8: Choice of electives & & .44 & \\
\hline Q9: Choice of profession & & & .89 \\
\hline Q10: Career choice & & & .51 \\
\hline Q11: Life after high school & & & .45 \\
\hline Q12: Duties & .59 & & \\
\hline Q13: Abilities & .57 & & \\
\hline Q14: Working conditions & .67 & & \\
\hline Q15: Education and training & .53 & & \\
\hline Q16: Ways to get into the profession & 63 & & \\
\hline Q17: Starting salary & .61 & & \\
\hline Q18: Potential to grow & .70 & & \\
\hline Q19: Working hours & .62 & & \\
\hline
\end{tabular}


The second planning factor involves activities that are more directly related to the seventh-grader student's present or immediate future. The results of their implementation, affect career development aspects of near life perspective. These are activities related to the real-life at school. They include achieving good academic results in subjects to which the young man relates his or her active working life, participating in similar curricular and extracurricular activities and choosing the appropriate electives. It is also in the nearer future for the seventh-grader to find the necessary information, seek the help of competent adults and discuss any possible problems in achieving his or her professional goals. Based on the above discussion, we define this factor as "Short-Term Career Planning".

The third factor is constituted by two choices of longer-lasting nature for the seventh-grader. On one hand, these are choosing a suitable profession in which the young person will play his or her main part as an adult, and on the other hand, choosing a career as a style of work behaviour. The specifics of these choices give us reason to define this factor as "Long-Term Career Planning."

The exploration of a professional career in seventh-graders is determined by two factors (Table 3 ). One of them includes all those information sources whose functioning is regulated in a certain way. The career information they receive is based on publicly recognized authority. Behind each source, there is a social experience channelized into socially acceptable forms. This includes educational representatives such as education professionals (vocational guidance experts and pedagogical advisors) and teachers. They have publicly recognized powers and obligations to facilitate and support the career development of adolescents. People in the preferred profession can also be included in this group of sources. The authoritativeness of the professional information coming from them is based on its real dimensions. With written sources, electronic and social media, the credibility of the information to a certain extent, is also publicly guaranteed. This factor is defined as "Institutionalized Sources".

\begin{tabular}{|l|c|c|}
\hline Table 3. Factor analysis of the Career Exploration Scale & Factor 1 & Factor 2 \\
\hline Questions & & .67 \\
\hline Q20: Parents, relatives - the importance & .56 & .52 \\
Q21: Peers, friends - the importance & .62 & \\
Q22: Education professionals - the importance & & .34 \\
Q23: Teachers - the importance & .54 & \\
Q24: Adults outside school - the importance & .58 & \\
Q25: Written sources - importance & .46 & .63 \\
Q26: Electronic and social media - the importance & & .47 \\
Q27: People in the preferred profession - the importance & .41 & \\
Q28: Parents, relatives - usefulness & .46 & .31 \\
Q29: Peers, friends - usefulness & & \\
Q30: Education professionals - usefulness & .38 & \\
Q31: Teachers - usefulness & .61 & \\
Q32: Adults outside school - usefulness & .41 & \\
Q33: Written sources - usefulness & & \\
Q34: Electronic and social media - usefulness & \\
Q35: People in the preferred profession - usefulness & \\
\hline Source: Authors & \\
\hline
\end{tabular}

The other factor in the study includes the information sources that the young person encounters in their communication. Contact with these sources is more spontaneous. The authoritativeness of the information received is not always publicly guaranteed. This factor can be defined as "Informal Sources".

\section{Conclusion}

The analysis of the results of the conducted study on career development of seventh-graders gives scientific reasons to draw several significant conclusions about the characteristics of career development of students in the process of transition to upper secondary education.

Seventh-graders prefer to plan steps, related to pursuing professional intentions that are directly linked to the learning activities or have a similar behavioral model. They significantly prevail over activities that require real work participation. Seventh-graders have a more accurate idea of the internal and external conditions for attaining the main career goal (education and training, abilities, duties of people practising the preferred profession, ways to get into it and working conditions) than of the more specific goals in career development (working hours, starting salary etc) and the ways and means to achieve 
them (ways to get into the profession). In career planning, a dominant role is played by the sources outside the educational field. There are objective prerequisites for seventh-graders to form an inadequate idea of their preferred profession and career.

This study of the career development of seven-graders reveals the multidimensional, complex and multideterminant nature of an individual's relationship with work. Our study justifies and underlines the essential relationship between career development as a personal process and vocational guidance. To fulfil its social mission the organized activity assisting in choosing a profession and career is based on the laws that characterize the process. At the same time, the achieved level of career development, the so-called career maturity, is a criterion for the effectiveness of the socio-pedagogical system of vocational guidance in preparing students for an active life after leaving high school.

\section{References}

Jordaan, J.P., \& Heyde, M.B. (1979). Vocational maturity in the high school years. N.Y.: Teachers College Press.

Lokan, J. (1984). Career Development Inventory. Hawthorn, Vic.: ACER.

Hughes, K. L., \& Karp, M. M., (2004). School-based career development: A synthesis of the literature. N.Y.: Institute on Education and the Economy, Columbia University.

Lent, R. W., \& Worthington, R. L. (1999). Applying career development theories to the school-to-work transition process. The Career Development Quarterly, 47, 291-296.

Savickas, M.L. (1994). Measuring career development: current status and future directions. The Career Development Quarterly, 43(1), 54-62.

Super, D.E., Thompson, A.S., Lindeman, R.H., Jordaan, J.P., \& Myers, R.A. (1981). Career Development Inventory. Palo Alto, Calif.: Consulting Psychologist Press.

Tang, M., Pan, W., \& Newmeyer, M. D. (2008). Factors influencing high school students' career aspirations. Professional School Counseling, 11(5), 285-295.

Wimberly, G. L., \& Noeth, R. J. (2005). College readiness begins in middle school. ACT policy report. Ames, IA: American College Testing (ACT), Inc. 